\title{
Social Influences on the Mate Choices \\ of Male and Female Japanese Quail
}

\author{
Bennett G. Galef, Jr. \\ McMaster University
}

\begin{abstract}
For the last decade, Japanese quail (Coturnix japonica) have served as subjects in an extended series of studies of social influences on reproductive behavior. The results of those studies are summarized here. Females prefer to affiliate with males that they have seen courting and mating, whereas males avoid females that they have seen courting and mating, and both males and females prefer to copulate with the same individuals with whom they prefer to affiliate. Further, females lay more fertilized eggs after mating with a male they have seen mate with another female than after mating with a male they did not watch while he mated. Female quail's preferences among males are also affected by observation of males' aggressive interactions, with virgin females preferring dominant males and sexually experienced females preferring subordinates. Evidence is provided suggesting that: (1) responses of quail to observation of a member of the opposite sex mating is an adaptive specialization of information processing systems involved in quail social learning and (2) mate-choice copying in quail can influence the evolution of male secondary sexual characteristics.
\end{abstract}

Keywords: Japanese quail, reproductive behavior, mate choice, observational learning, video-to-objects, adaptive value of social learning.

The possibility that socially acquired information might affect animals' reproductive choices was first raised by field biologists who observed birds that, like sage grouse (Centrocerus urophasianus) or black grouse (Tetrao tetrix), mate on "leks," locations that provide nothing of value to females other than: (1) opportunities to observe males display, and (2) male gametes. On the typical avian lek, although many males compete to mate with visiting females, a small number of males acquire a grossly disproportionate share of matings. For example, on one lek, where 10 male white-bearded manikins (Manacus manacus trinitatis) were displaying, a

The research described here was supported by generous grants from the Natural Sciences and Engineering Research Council of Canada. I thank the many students who have contributed to these studies, particularly David White (now at the University of Pennsylvania), Kamini Persaud (now at the University of Toronto), Alex Ophir (now at the University of Florida), Geoffrey Gilbert (still at McMaster University) and Sara Watkins (now at the University of Alberta) for their participation. Without their devotion to this work, absolutely nothing would have been accomplished.

Correspondence concerning this article should be addressed to Bennett Galef, Jr., Department of Psychology, Neuroscience \& Behaviour, McMaster University, Hamilton, Ontario, Canada. L8S 4K1 E-mail: galef@mcmaster.ca single male achieved 330 of 438 observed copulations, while six other males together secured only 10 copulations (Lill, 1971).

Often, it is not obvious why a particular male on a lek is preferred by visiting females. Human observers, at least, have difficulty finding physical or behavioral characteristics that would predict the overwhelming success of particular males in the competition for access to females (Gibson et al., 1991). Consequently, several investigators have suggested that some males are so much more successful than others because females visiting leks tend to copy one another's mate choices (e.g., Bradbury \& Gibson, 1983; Gibson et al. 1991; Hoglund et al. 1992, 1995). If females choose to mate with a male whom they have seen mating with other females, then once a male is fortunate enough to attract a first female, other females are more likely to choose him as a partner, and the process has the potential to snowball, giving fortunate males the opportunity to garner far more reproductive success than their phenotypes would predict.

\section{Informational Cascades}

Such skewing of reproductive behavior would be an example of what, Hirschleifer (Bikchandani et al., 1992) has called an "informational cascade" that occurs when an in- 
dividual that has observed the actions of others copies their behavior without attending to any private information it may have as to the possible consequences of pursuing alternative courses of action. If the costs associated with sampling alternatives are relatively high and there is relatively little difference between the consequences of alternatives, simply copying the behavior of others that have made a decision can be a rational strategy (Gibson \& Hoglund, 1992; Nordell \& Valone, 1998).

Despite some admirable efforts, for example Hoglund et al.'s pioneering field experiments with black grouse (Hoglund et al. 1992, 1995), or Gibson and Bradbury's (Gibson et al., 1991) work with sage grouse, it has proven difficult in uncontrolled natural environments to demonstrate that females on leks actually participate in informational cascades, uncritically copying one another's mate choices. Possibly, the females attending a lek simply find the same male most attractive, and we humans have yet to discover the cues that females are using when choosing mates. Possibly, females are all choosing to mate with males that occupy what females see as the best positions in a lek, and so on. In uncontrolled field situations, it is challenging to exclude all alternatives to mate-choice copying.

\section{Mate-choice Copying in Guppies?}

It is however, relatively easy to demonstrate mate-choice copying in the laboratory. Lee Dugatkin was the first to undertake such work using the guppy (Poecelia reticulata) as a model species. Dugatkin and his collaborators have repeatedly found that female guppies from a low-predation site on the Turure River in Trinidad show an increased tendency to affiliate with a male after seeing him mate with another female (e.g.; Dugatkin, 1992; Dugatkin \& Godin 1992; Amlacher \& Dugatkin, 2005), although female guppies in other laboratories do not seem to behave similarly (e.g. Brooks, 1996, 1998; Lafleur et al., 1997). Such contradictory results are interesting, suggesting the need for additional work to describe as yet undiscovered variables that affect the probability of mate-choice copying. However, I will not discuss that rather general problem here. Rather, I shall describe a research program undertaken in my own laboratory investigating both mate-choice copying, and other kinds of social influences on reproductive behavior of Japanese quail (Coturnix coturnix).

\section{Mate-choice Copying in Japanese Quail}

For the past 12 years, my graduate students David White, Alex Ophir, Kamini Persaud, Geoffrey Gilbert and I, as well as several undergraduate students working in the laboratory, have been interested in determining whether the reproductive decisions of Japanese quail are influenced by observa- tion of the mating behavior of others of their species.

\section{The subjects}

Why Japanese quail? Japanese quail are not particularly beautiful birds (Fig. 1). They are, however, quite wonderful birds for laboratory investigations of sexual behavior. Females in the overwhelming majority of birds and mammals have cycles of receptivity; they are interested in males only a few times a week, or for only a few months each year, and males find females more or less attractive depending on where the females are in their reproductive cycles. Such variability in sexual behavior and attractiveness makes it difficult to conduct controlled studies, even in the laboratory.

Such problems are avoided with Japanese quail. Like guppies, mature Japanese quail kept on a long day-night cycle, say 16 hours of light each day, are willing to court and mate essentially whenever given an opportunity to do so. Put a male quail together with a conspecific female, and they will almost inevitably proceed to increase their individual fitness. Consequently, experiments can be conducted on factors affecting reproductive decisions in Japanese quail that would be considerably more difficult with most mammals or other birds.

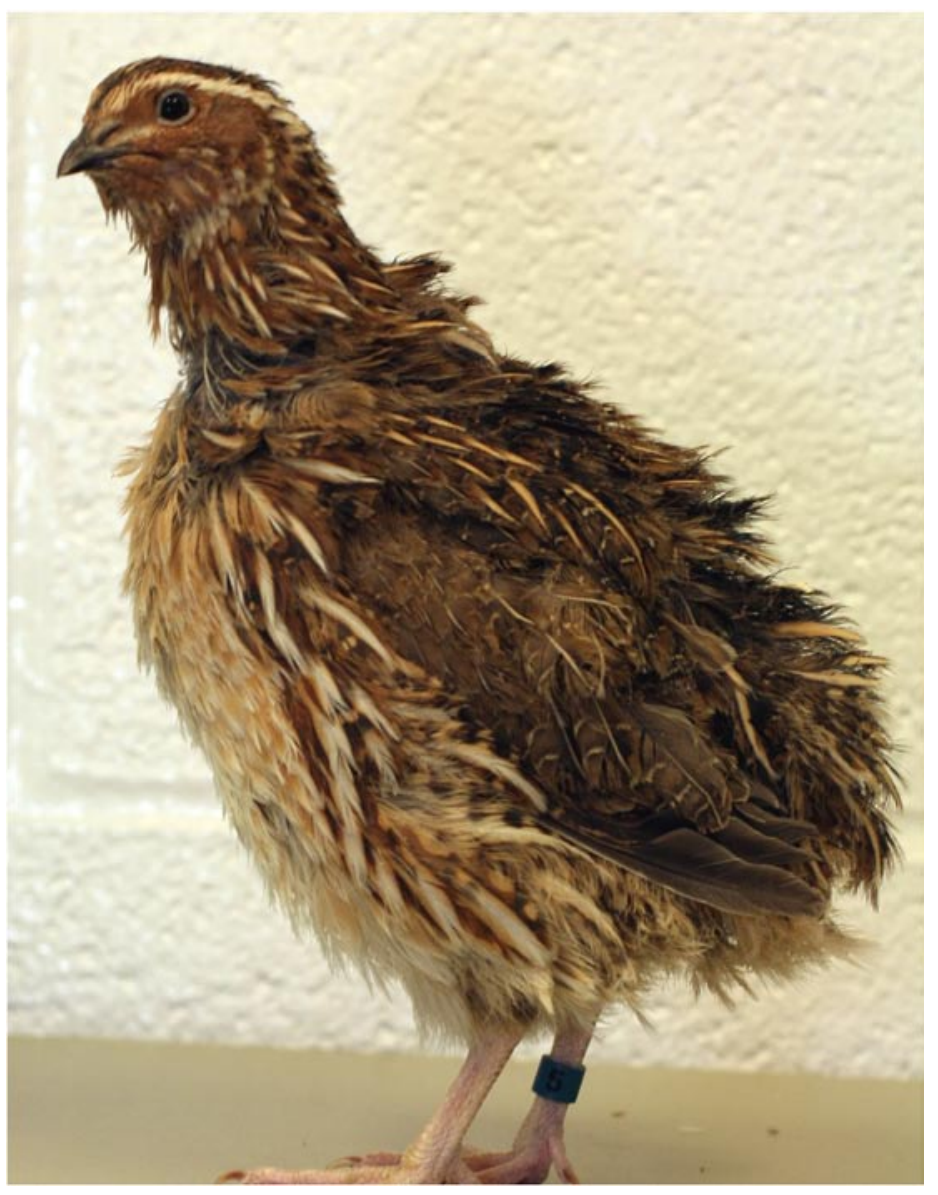

Figure 1. A male Japanese quail (Cotrunix japonica). 
It is, probably important to point out that Japanese quail are not perfect animals for behavioral studies. The Japanese quail available to us have been domesticated for more than 1000 years in Japan, and free-living, wild Japanese quail are quite reclusive (Crawford et al. 1997). Consequently, little is known of the social organization or sexual behavior of genetically wild populations, and there is no way to know whether results of studies of domesticated Japanese quail in the laboratory accurately reflect the behavior of their wild forebears living in natural circumstances. None-the-less, the sexual behavior of domesticated quail in laboratory situations has proven quite interesting, and perhaps, more susceptible to social influences of various kinds than might be expected.

\section{The Apparatus}

The apparatus that my students and I use to look at social influences on mate choice in quail is illustrated in overhead schematic in Figure 2. It is a cage divided into three sections by two screen partitions. The central compartment contains a transparent Plexiglas holding cage that can be raised using a string and pulley arrangement to release a quail confined within it. Closed-circuit television allows us to watch the birds and to record and score their behavior without disturbing them.
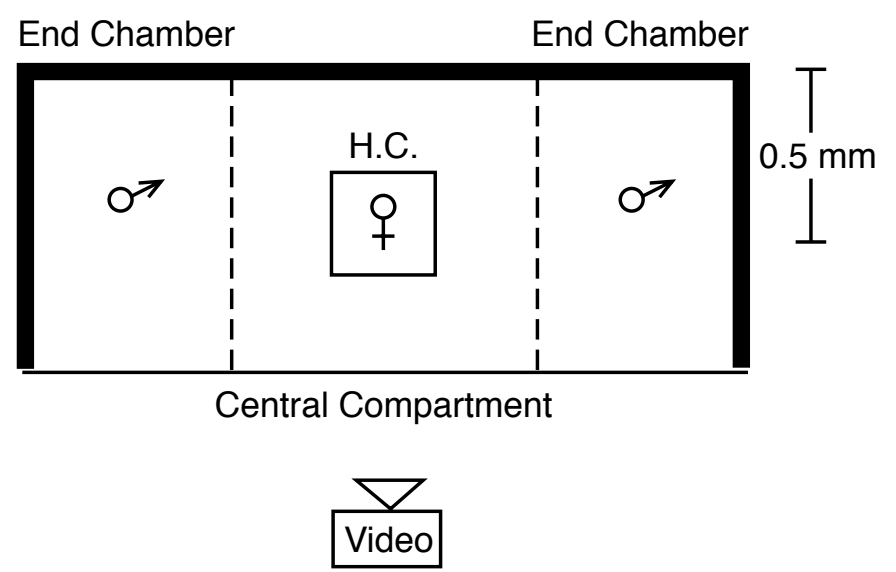

Figure 2. Overhead schematic of apparatus used to study social influences on mate choice in Japanese quail. From Figure 1, 546, "Mate-choice copying in the Japanese quail, Coturnix coturnix japonica," by B. G. Galef, Jr. and D. J. White, Animal Behaviour, 55, 545-552. Copyright 1998 by Elsevier Ltd. Adapted with permission.

\section{The Procedure}

Many of the experiments that I will be describing consisted of 3,10-minute phases. The first phase was a pretest that we used to determine a focal animal's preference between two members of the opposite sex. To start the pretest, we confined a focal animal in the holding cage and placed one member of the opposite sex in each of the two end compartments of the apparatus. We then raised the holding cage allowing the focal animal to escape and move freely about the central compartment. We simply recorded how much time the focal animal spent on the side of the central compartment that was closer to each of the two end compartments.

The second phase was an observation phase during which the focal animal was confined in the holding cage and given the opportunity to observe one of the two target animals remain alone and the other target animal court and mate with what we refer to as a "model" animal. A model animal is just another quail of opposite sex from a target animal.

The third and final phase is a posttest during which the focal animal gets to again choose between the same two target animals that it had chosen between during the pretest.

In our first experiment, we simply determined whether a focal female Japanese quail would show a change in preference for a male quail after she had seen him court and mate with a model female during the observation phase.

Focal females chose between pairs of males during the pretest. During the observation phase, half the focal females, those that we had randomly assigned to the experimental group, watched the target male that they had not preferred during the pretest court and mate with a model female. We treated focal females assigned to the control group exactly as we treated focal females assigned to the experimental group except that, during the observation phase, we did not place a model female with either target male.

\section{The Results}

The results of this first experiment are presented in Figure 3. As can be seen in the figure, females assigned to the experimental group (those that had seen a target male court and mate with a model female during the observation phase) showed a marked increase between pretest and posttest in the time that they spent with the target male they had seen mating during the observation phase. Females assigned to the control group (those that had not seen a target male court and mate during the observation phase) showed no change between pretest and posttest in the time that they spent with target males (Galef \& White, 1998).

Is this change in behaviour seen in focal females sufficient to establish that female quail are mate-choice copying? Of course not. Males that have recently courted and mated may look or act differently from males that have not, and females find males that have recently courted more attractive. 


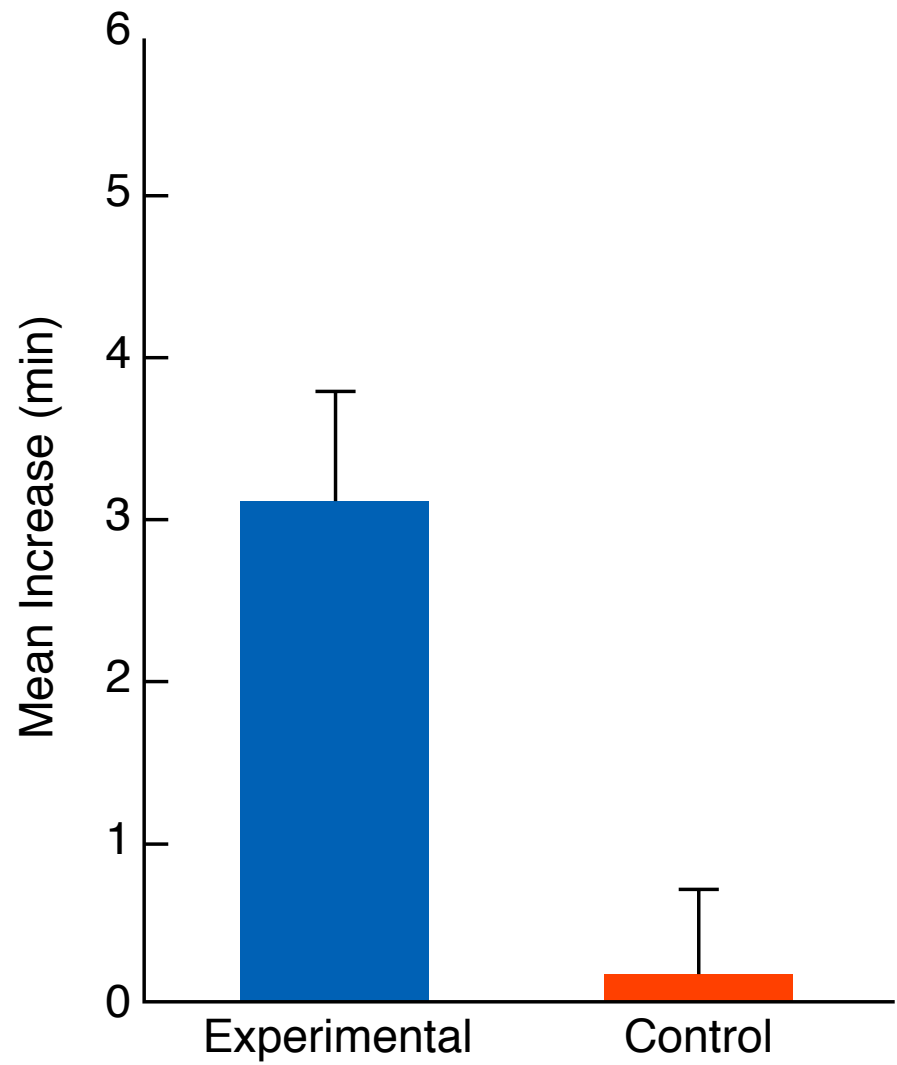

Figure 3. Mean change from pretest to posttest in the minutes that focal females spent with the target male that they did not prefer. During the observation phase, focal females assigned to the experimental condition observed the target male that they did not prefer court and mate with a model female; those assigned to the control group did not. Flags $= \pm 1$ SEM. From Figure 2, 549 "Mate-choice copying in the Japanese quail, Coturnix coturnix japonica," by B. G. Galef, Jr. and D. J. White, Animal Behaviour, 55, 545-552. Copyright 1998 by Elsevier Ltd. Adapted with permission.

\section{Controls for Effects of Mating on the Behavior and Appearance of Males}

We compared the behavior of focal females that, during the observation phase, could either see one of their target males copulate with a model female or had opaque walls attached to two sides of the holding cage blocking the focal female's view of target males during the observation phase. As can be seen in Figure 4, focal females that actually saw a target male mate showed a significant increase in the time they spent with that male during the posttest. Focal females that could not see a target male while he mated with a model female during the observation phase did not show any increase in the time they spent with the male that mated (Galef $\&$ White, 1998). So mating per se does not change the subsequent behaviour or appearance of target males to make them more attractive to focal females.

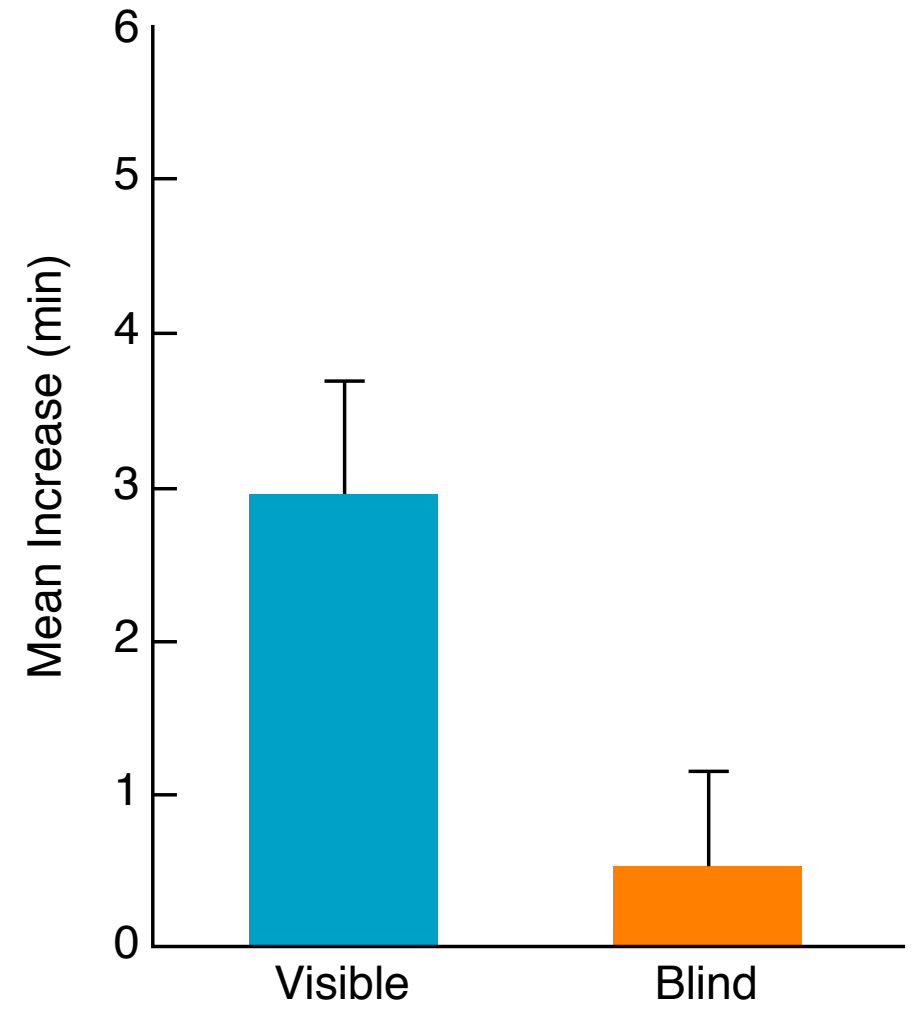

Figure 4. Mean change from pretest to posttest in the minutes that focal females spent with the target male they did not prefer. During the observation phase, focal females assigned to the visible group could see their non-preferred target male while he courted and mated with a model female; focal females assigned to the blind group could not. Flags $= \pm 1$ SEM. From Figure 4, 551, "Mate-choice copying in the Japanese quail, Coturnix coturnix japonica,” by B. G. Galef, Jr. and D. J. White, Animal Behaviour, 55, 545-552. Copyright 1998 by Elsevier Ltd. Adapted with permission.

We have approached the question of whether the appearance or behavior of males are changed after they mate so as to make them more attractive or females prefer males that they have actual seen mating with others in a second way. To begin, we made 5-minute video recordings of each of the males that we planned to allow focal females to choose between both standing alone and mating with a model female, thus creating a library of quail pornography that we stored in our computer.

We then allowed focal female quail to choose between two target males in our standard pretest of preference. During the subsequent observation phase, each focal female watched a videotape of one of the target males she did not prefer during the pretest mating with a model female. During the posttest, we gave the female a choice between the same two target males that she had chosen between during the pretest.

As can be seen in Figure 5, females that saw a video of their non-preferred target male mating on an thin-film transistor monitor, showed an increase between pretest and post- 
test in the time they spent near that male as great as that shown by focal females that had watched one of their target males mate live during the observation phase. To the contrary, females that, during the observation phase, watched a videotape showing one of their target males remaining alone in his cage showed no change from pretest to posttest in the time they affiliated with that target male (Ophir \& Galef, 2003a). So far as we know, this is the first demonstration in birds of transfer of a learned discrimination between video images and real objects. preference for a male seen mating, not for the place where they saw either two conspecifics or conspecifics mating.

Further, as shown in the 'third-male' bar in Figure 5, females that watched an unfamiliar male mate on videotape during the observation phase showed no change from pretest to posttest in the relative amount of time that they spent near each of their target males (Ophir \& Galef 2003a). So simply watching other birds mate doesn't somehow change a female's preferences. It is getting hard to avoid the conclusion that female quail copy one-another's mate choices.

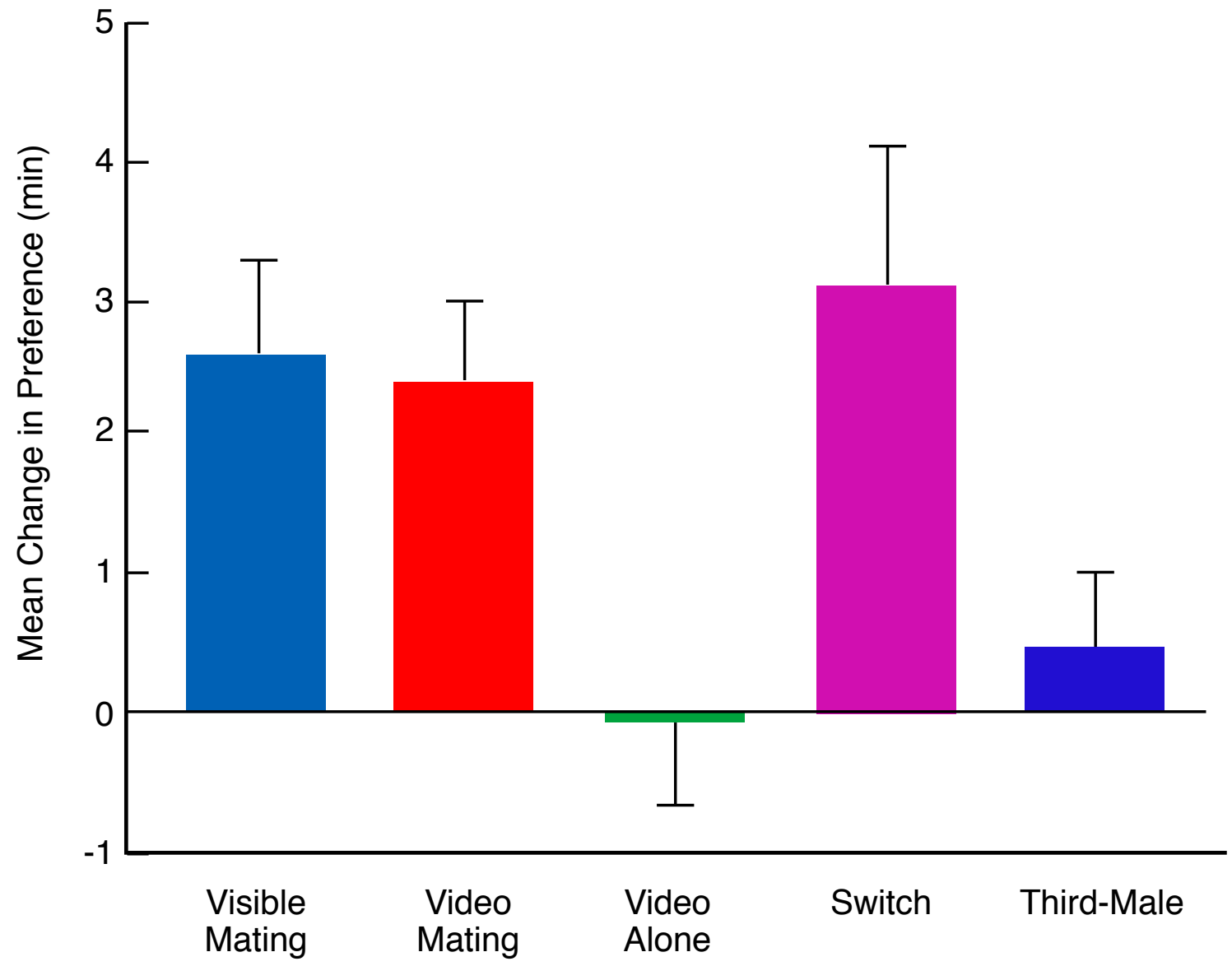

Figure 5. Mean change from pretest to posttest in the minutes focal females spent with the target male they did not prefer. During the observation phase, focal females assigned to the live group saw their non-preferred target male mate. Focal females assigned to all other groups saw a male on a television monitor. Females assigned to the: (1) video-mating group saw their non-preferred target male mate, (2) video-alone group saw him standing alone, (3) switch group saw him mate, but he changed location between pretest and posttest, and (4) third male group saw a male other than a target male mate. From Figures 3 and 4, 372-373, Error bars show the standard error. "Female Japanese quail affiliate with live males they have seen mate on video" by A. G. Ophir and B. G. Galef, Jr., Animal Behaviour, 66, 369-375. Copyright 2003 by Elsevier Ltd. Adapted with permission.

As shown in the 'switch' histogram in Figure 5, if we switched the location of target males between the pretest and the posttest, we still saw a significant increase between pretest and posttest in the time that females affiliated with the target male seen on videotape. (We have done the same experiment using live rather than videotaped during the observation period, and found the same result (Galef \& White, 1998, White \& Galef, 1999b). So females are developing a

\section{Male "Mate-choice Copying"}

We have also looked at effects on the mate choices of focal male quail of seeing target females mate. After all, if females like popular males, perhaps males like popular females. The experiments were identical to those just described examining social effects on mate choices of females, with two exceptions: first, when studying mate choices of males, during 
both pretest and posttest, we allowed focal males to choose between target females. Second, we allowed focal males to watch one of their target females mate with a model male during the observation phase.

As those with an ecological or evolutionary bent might predict, the effect on males of watching a member of the opposite sex mate is exactly the opposite of its effect on females. After a focal male watches a target female mate with a model male during the observation phase, he is markedly less attracted to her. Once again, it is not that a female changes in behavior or appearance after mating to become less attractive to a focal male. As can be seen in Figure 6, focal male quail that saw a target female mate during the observation phase showed a significant decrease (not an increase) from pretest to posttest in the time that they spent with her. Focal males that could not see target females during the observation phase while one of them mated with a model male showed no change in affiliative preference. Apparently, mating per se does not change the behaviour or appearance of females to make them less attractive to focal males (White \& Galef, 1999c).

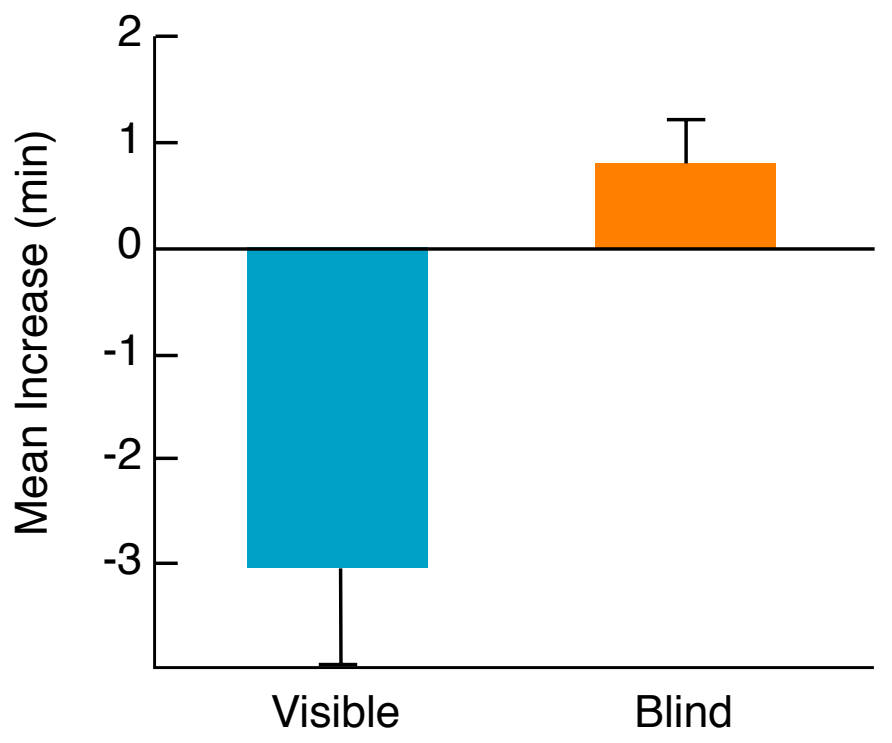

Figure 6. Mean change from pretest to posttest in the minutes that focal males spent with the target female that they preferred. During the observation phase, focal females assigned to the visible condition observed the target male that they preferred while he courted and mated with a model female; those assigned to the blind group did not. Flags $= \pm 1$ SEM. From Figure 3, p. 1009, "Social effects on mate choices of male Japanese quail," by D. J. White, and B. G. Galef, Jr.,. Animal Behaviour, 57, 1005-1012. Copyright 1999 by Elsevier Ltd. Adapted with permission.

\section{Affiliative Preference or Mate Choice?}

I introduced this paper as relevant to mate-choice copying. However, so far, I have provided data only on affiliative preferences of females and males, not their actual choices of partners for reproductive behavior. Although it has become almost traditional in the mate-choice literature to equate affiliation with reproduction, that is really not quite good enough.

In our studies of social effects on sexual behavior per se, we first allowed a focal female to choose between two target males for 10-min in our standard apparatus to test their affiliative preference. We then allowed the same focal female to choose for $10 \mathrm{~min}$ between the same two target males when they were tethered at opposite ends of a straight alley. The focal female could run up and down the alley and mate with whichever male she wished. Regardless of what measure of female mate choice we used -- the first male the female allowed to mate with her, the last male the female allowed to mate with her, or the male that a female mated with more frequently -- the target male that a female spent more time close to in the affiliative choice test was the male that she mated with most often during a 10-min test (White \& Galef 1999a: Figure 7).

Similarly, males free to mate with both their preferred and non-preferred target females (as determined in a 10-min affiliative-preference test) preferred to mate with the target female that they remained near during a preceding test of affiliative preference (White \& Galef 1999a).

However, even evidence that quail prefer to mate with the same individuals that they prefer to affiliate with is not quite good enough. Copulation does not always result in fertilization of a female's ova, and fertilization is what mate choice is really all about. Indeed, the disjunction between copulation and fertilization is particularly salient in birds, because some female birds, Japanese quail among them, are able to eject sperm from their reproductive tracts after they have been inseminated by a male (though in Japanese quail observable sperm ejection has not been shown to effect female fertilization rates). In any case, insemination by a male need not lead to fertilization of a female's ova and effects of female preference on the fertilization success of males as well as on female affiliation and female choice of a partner for copulation need to be examined.

We allowed a female quail to choose between two males for $10 \mathrm{~min}$ in our standard test of affiliative preference. Next, we placed that female in an enclosure with either her preferred male or her non-preferred male for $10 \mathrm{~min}$, and allowed the pair to mate. Then, we put the female back in her home cage and collected all of the eggs that she laid for the next 10 days, and after 5 days of incubation, opened 
A.

B.

C.

First Copulation

\section{Last Copulation}

Majority of
Copulations
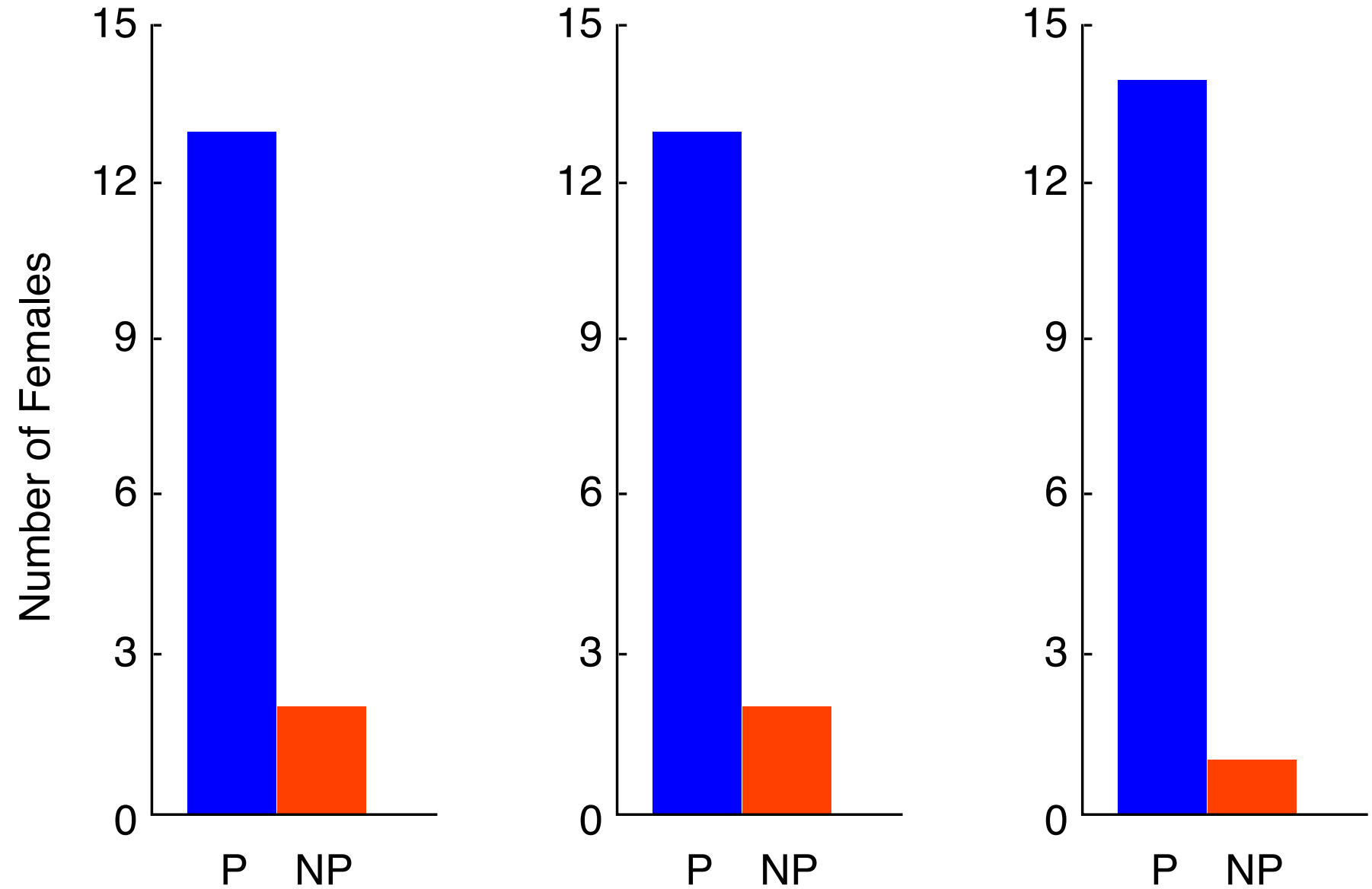

Figure 7. Number of females out of 15 that copulated (a) first, (b) last and (c) more often with the male that they had preferred or did not prefer in a test of affiliative preference. From Figure 3, 868. "Affilitative preferences are stable and predict mate choices in both sexes of Japanese quail, Coturnix japonica," by D. J. White, and B. G. Galef, Jr., Animal Behaviour, 58, 865-871. Copyright 1999 by Elsevier Ltd. Adapted with permission.

the eggs and determined whether they had been fertilized. The percentage of females laying fertilized eggs was much higher when we had allowed females to mate with their preferred than with their non-preferred males, despite the fact that females copulated equally often with their preferred and non-preferred males during the 10 min that they were placed together (Persaud \& Galef, 2005a: Fig. 8).

Perhaps more interesting with regard to social influences on reproduction, we found that females forced to mate with their respective non-preferred males after watching while he mated with a model female laid more fertilized eggs than did females that could not see their non-preferred male while he mated with a model female.

During a pretest, we allowed focal females to choose be- tween two target males, and during the observation phase permitted each female either to see or not to not see while their respective non-preferred males each mated with a model female. Then, we placed each focal female with her non-preferred male for $10 \mathrm{~min}$ to mate. Last, we collected and incubated all of the eggs that each focal female laid and determined whether each was fertilized. As can be seen, in Figure 8, focal females that had seen their non-preferred male mate during the observation phase were more likely than were females that had not to lay fertilized eggs Persaud \& Galef, 2005a).

\section{Evidence of Adaptive Specialization of Social Learning}

Female quail increase their preference for male quail that they have seen mating, presumably because there is some 


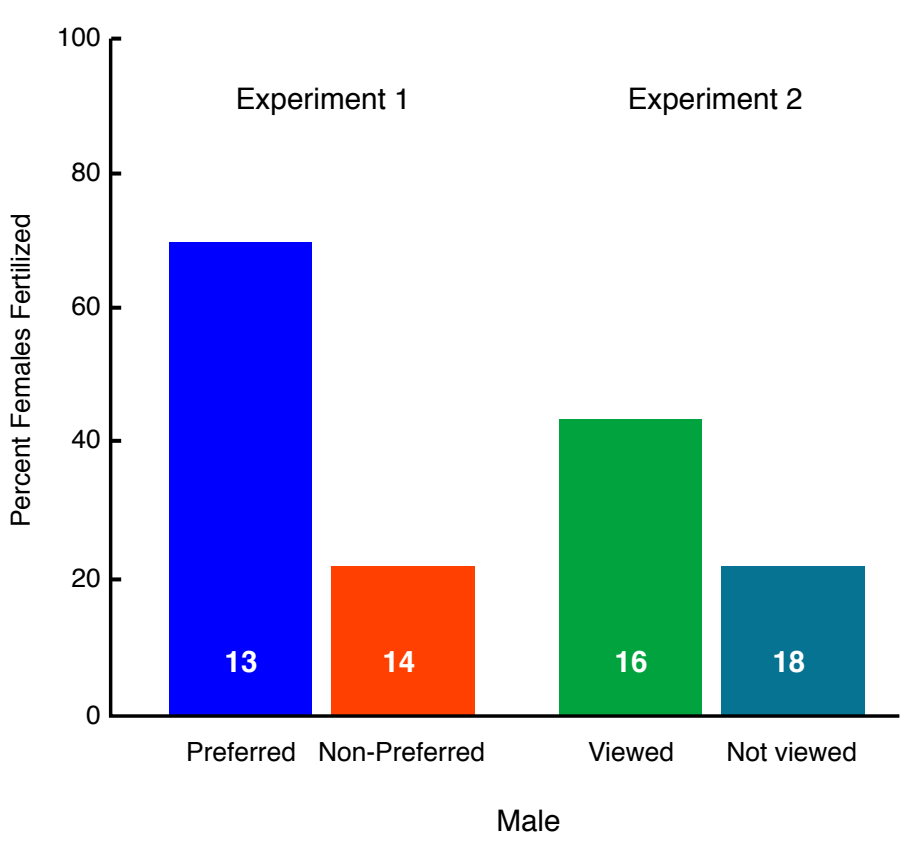

Figure 8. Percentage of females laying fertilized eggs after (Experiment 1) pairing with either a referred or nonpreferred male and (Experiment 2) pairing with a nonpreferred male either viewed or not viewed while he mated with another female. From Figure 2, 253, "Eggs of a female quail are more likely to be fertilized by a male that she prefers," by K. N. Persaud, and B. G., Galef, Jr. Journal of Comparative Psychology, 119, 251-256. Copyright 2005 by American Psychological Association. Adapted with permission.

cost to female quail that is associated with detecting and selecting high quality males with whom to mate, and copying the mate choices of others reduces that cost (Gibson \& Hoglund, 1992). Conversely, male quail show a decrease in their attraction to females that they have seen mating, presumably because a male is less likely to fertilize the eggs of a female after she has been inseminated by another male. Indeed, evidence in the literature indicates that, for several hours after a female bird (in this case a chicken) has mated with a male, copulations with other males are relatively unlikely to fertilize her eggs. However, as time passes, the probability of a second partner fertilizing a female's eggs rises, and by roughly $24 \mathrm{~h}$ after copulating with a first male, the probability of a female's eggs being fertilized by a second male returns to baseline (Birkhead, 1988; Birkhead \& Moller, 1998).

Based on such functional considerations, we predicted that a focal male's aversion to mating with a female that he had seen mate with a model male would dissipate rapidly, because after 24 hours, a female seen mating would be more or less as likely to be fertilizable as she was before she copulated. On the other hand, a focal female's enhanced preference for a male that she had seen mating should last a relatively long time. If a male is a relatively good male to mate with on Tuesday, he should still be a good male to mate with on Thursday, unless the environment has changed or a new, superior male has appeared on the scene.

The experiments are exactly like the first of our experiments described above, except that we introduced a 48-hour delay between the observation stage, when a focal animal observed one of two target animals mate, and the posttest, when the focal animal chose for the second time between the same two target chosen between during the pretest.

We found that focal females that saw a target male mate with a model female during the observation phase showed an increased preference for him both immediately afterwards and 48 hours later. To the contrary, focal males that had seen a target female mate with a model male during the observation phase avoided her immediately after seeing her mate, but, $48 \mathrm{hr}$ later, had forgiven her affair (White \& Galef, 2000b). So, not only do males and females respond differently to seeing members of the opposite sex mate, they also seem to respond differently to that experience as a function of the time since it has occurred. Focal males and focal females both see the same thing. They see a pair of quail mating. The response of the female is to form a long-lasting, increased preference for the male that she saw mating. The response of the male is to form a transitory aversion to the female that he saw mate. It seems reasonable to conclude that differences between male and female Japanese quail in both the direction and duration of their responses to seeing members of the opposite sex mate reflect adaptations of the information-processing systems that support social learning.

\section{A Biologically Interesting Instance of Stimulus Generalization}

The theoreticians tell us, that for social learning to play a role in the evolution of male secondary sexual characteristics, females must show an increased probability of mating not only with a particular male she has seen mate, but also with other males that share his distinctive characteristics (e.g. Boyd \& Richerson, 1985; Brooks, 1998; Laland, 1994). For example, if a focal female sees another female mate with a large male, the focal female must develop an enhanced preference for large males in general, not just for the particular large male she has seen mating, if her socially induced change in mate preference is to affect the evolution of male characteristics at the population level.

The quail we purchase from a local farm, where they are raised in vast numbers for the gourmet market, usually have pigmented feathers all over their bodies. However, we often find birds with a white feather or two. The cause of such unusual feather coloration is well understood and reflects the effects of single-gene mutations. 
We have created what we think of as "pseudo-mutant" male quail by gluing some white feathers onto the tops of the heads of otherwise normally pigmented male quail. We then let each of a group of focal females watch while a pseudo-mutant male mates with a model female, and then ask how this experience changes the focal female's response to pseudo-mutant males in general.

We used the same apparatus that we had used in all of our previous experiments but with a small "ancillary cage" attached to the back of the central compartment of the enclosure in which we could confine a pseudo-mutant male and his partner (See Figure 2). During an observation phase, we allowed a focal female watch a pseudo-mutant male mate during a 10-minute observation period, then blocked the focal female's view of the mating pair and let her choose for 10 min between, unfamiliar an pseudo-mutant male and a control male confined in opposite end compartments of the apparatus. We found that focal female quail showed an enhanced preference for any male pseudo-mutant after watching one male pseudo-mutant mate (Figure 9), whereas focal females that either watched a pseudo-mutant male standing alone during the observation phase or looked at an empty ancillary cage tended to avoid pseudo-mutant males (White

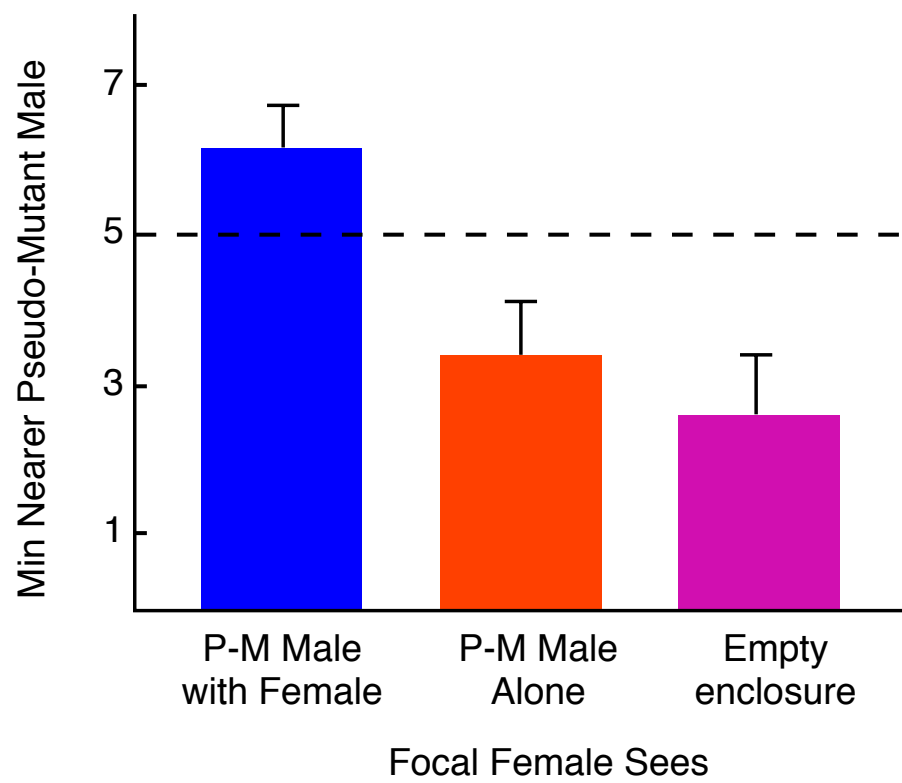

Figure 9. Mean minutes that a focal female given a choice between an unfamiliar control and pseudo-mutant (PM) male spent nearer the PM male after observing a PM male court and mate with a model female in the ancillary cage, a PM male alone in the ancillary cage or the ancillary cage empty. Flags $= \pm 1$ SEM. From Figure 3, 978, Dotted line indicates indifference to male presence. " 'Culture' in quail: Social influences on mate choices of female Coturnix japonica," by D. J. White and B. G. Galef, Jr. Animal Behaviour, 59, 975-979. Copyright 2000 by Elsevier Ltd. Adapted with permission.
\& Galef, 2000a). Godin et al. (2005) have recently reported a similar effect in guppies.

\section{Male Aggression and Female Mate Preference}

Mating in quail looks to humans to be a pretty violent business. Courting males chase and peck at females, seize feathers at the back of a female's head or at the end of her wings, and often drag her around before jumping onto her back to copulate. Given the nature of males courtship, females might be expected to try to avoid contact with males, except when they need sperm to fertilize their eggs.

We took a group of females and put some with males to mate, and over the next 10 days, examined the eggs the females laid to see if the eggs were fertilized. We then let each female choose between an unfamiliar male, randomly selected from among the males in our colony, in one end chamber of the apparatus (Fig. 2) and nothing in the other end chamber. We predicted that females laying fertilized eggs, and that therefore in no further need of contact with males, would spend less time near the male in the choice apparatus than either females laying unfertilized eggs or unmated females that both needed male gametes to reproduce. And that is what we found (Persaud \& Galef, 2004; Fig. 10).

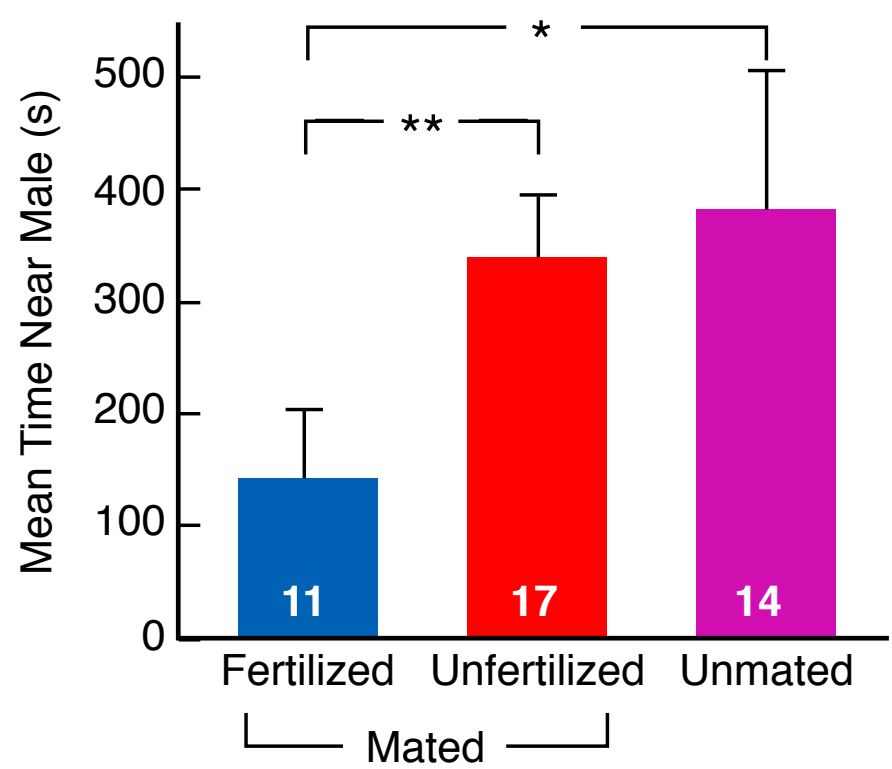

Figure 10. Mean time (seconds) that unmated females and mated females laying either fertilized or unfertilized eggs spent closer to the end compartment containing a male during the choice phase. Flags $= \pm 1$ SEM. From Figure 2, 1413, "Fertilized female quail avoid conspecific males: female tactics when potential benefits of new sexual encounters are reduced," by K. N. Persaud and B. G. Galef, Jr., Animal Behaviour, 68, 1411-1416. Copyright 2004 by Elsevier Ltd. Adapted with permission. 
We had also predicted that in the presence of a male, fertilized focal female quail given a choice between an end compartment containing a female quail randomly chosen from among females in our colony and an empty end compartment would spend more time near the female then either mated and unfertilized or unmated females. This prediction was based on an extrapolation from Hamilton's "selfish herd" phenomenon (Hamilton, 1971). If you are a female quail in the presence of a potentially sexually coercive male, and you do not want anything to do with him, the best place for you to be is as close to another female as possible.

Indeed, when a male was in the ancillary cage, focal females spent more time close to the end chamber containing a female than when a female was present in the ancillary cage or the ancillary cage was empty. Most interesting, I think, mated focal females laying fertilized eggs aggregated with another female when in the presence of a male, whereas focal females that were mated and laying unfertilized eggs, like females that had not been mated, did not tend to aggregate with others of their sex (Persaud \& Galef, 2004).

Of course, just because courtship in quail looks unpleasant to us is no guarantee that female quail find such behavior punishing. So, we have also done some work to determine whether female quail actually find unpleasant some of the behaviors in which males engage while courting and mating.

We allowed a female quail to mate with a male while we recorded their behavior on videotape, then scored each male's behavior for instances that looked to us to be potentially harmful to females (e.g. feather pulling, head pecking, jumping onto the female's back). Next, we offered the female a choice in our standard apparatus between the male she had copulated with and an unfamiliar male from our colony.

We predicted that the more obnoxious the male with whom a female had mated, the more likely she would be to avoid that male when offered the choice between him and another male. And that's what happened. The males that females avoided in a choice test had engaged more frequently in obnoxious behaviors while courting and mating than the males that females preferred to unfamiliar males (Persaud \& Galef, 2005b).

When we subsequently looked to see whether the obnoxiousness of males was related to their success in fertilizing females we found that, in fact, males that, while courting and mating, behaved aggressively towards females were less likely to fertilize a female's eggs than were males that were relatively less aggressive towards females. Thus, gentle males had a reproductive advantage relative to rough males, at least in Japanese quail (Persaud \& Galef, 2005b).
Why is this relevant to social learning? Because female quail can learn by observation which males are likely to behave aggressively towards them. We let a female quail watch a pair of males while the males contested their dominance to see what effects such eavesdropping on males has on females' later choices of mates. Two males in the ancillary cage pecked at one another through a transparent Plexiglas partition while a focal female watched, and she then chose between those two males after they have been moved to the end compartments of the apparatus (The literature indicates that the male that pecks more frequently at the Plexiglas barrier will also win an unrestrained fight (Schlinger et al., 1987), and we used the surrogate measure because staged aggressive encounters between animals are no longer permitted at my University. We found that sexually experienced females preferred the losers in dominance encounters, while sexually naïve females preferred the winners (Ophir \& Galef, 2004; Ophir et al. 2005).

The reason why experienced females' might prefer less aggressive males is straightforward. We took a group of 16 male quail and let them engage in a round-robin tournament. Each male pecked through the plastic barrier at each of the 15 other males and was then assigned a dominance ranking based on the number of bouts out of 16 that he won. We then paired each of the same 16 males with three females in succession and counted the number of pecks that he delivered to his partners and the number of potentially harmful behaviors other than pecking that the male engaged in while courting and mating. Finally, we examined the correlation between males' dominance ranks when interacting with other males and their aggressiveness when interacting with females (Ophir \& Galef, 2003b). As the data in Figure 11 indicate, by observing the aggressive interactions of a male with others of his sex, a female could predict the relative level of pecking and of other potentially harmful behaviors in which a male was likely to engage while courting. We interpret these results as suggesting that females can use information acquired by eavesdropping on males engaged in aggressive interactions to estimate the males' probable level of aggressiveness while courting, and that females learn to avoid potentially harmful, aggressive males.

\section{Conclusion}

In sum, we have found pervasive social influences on the reproductive behavior of Japanese quail, and are beginning to understand how and why social learning influences the reproductive decisions of Japanese quail, a species that we chose for study because of its suitability for laboratory research on sexual behavior. It will be interesting to see whether our findings generalize to other species and other circumstances. There is reason to suspect that the findings described here are not limited to quail confined in small cag- 


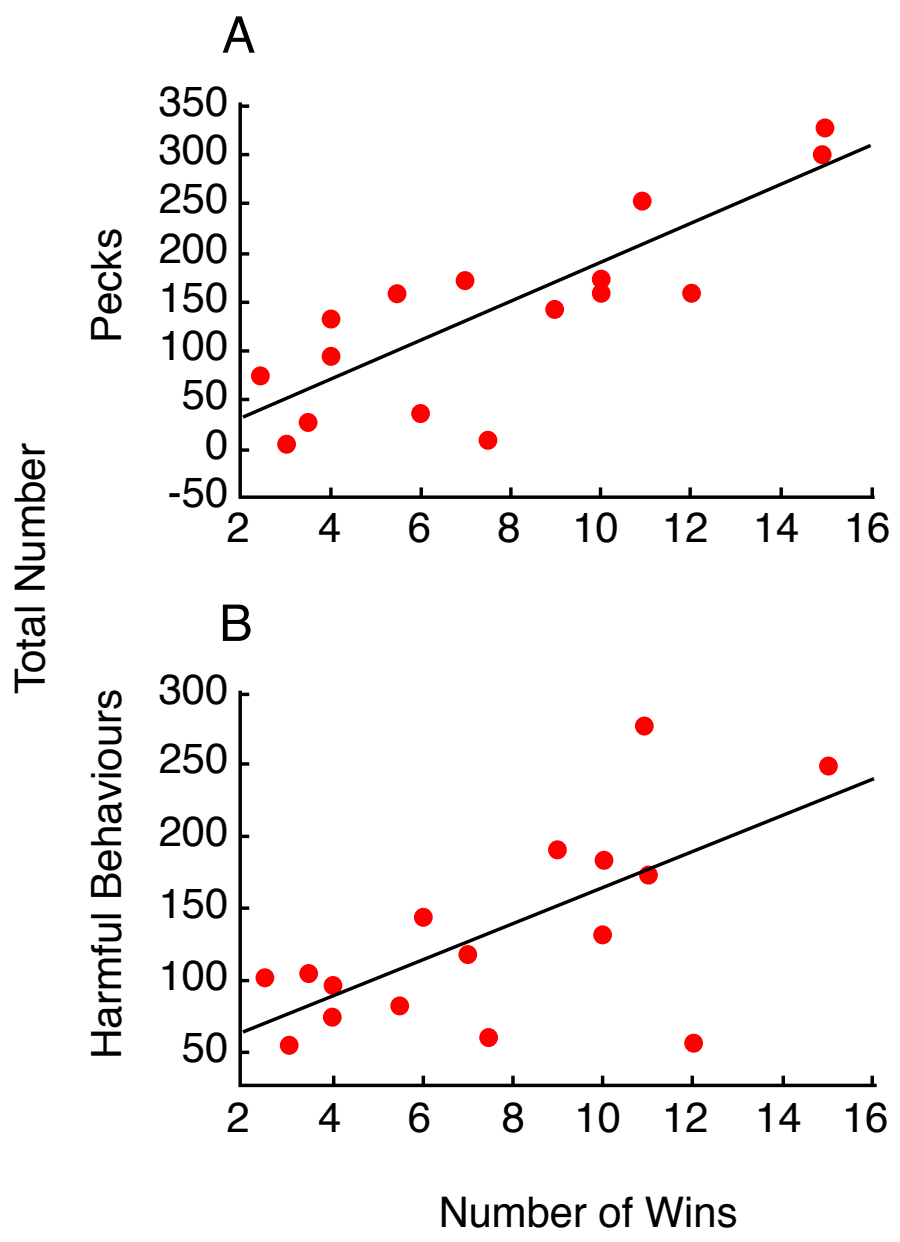

Figure 11. Scatter plots of the number of wins that a male achieved in a round-robin tournament with 15 other males and the number of (a) pecks and (b) other potentially harmful behaviors that he engaged in while courting three females. From Figure 5, 405. Ophir, A. G. \& Galef, B. G. Jr. "Female Japanese quail that 'eavesdrop' on fighting males prefer losers to winners," by A. G. Ophir and B. G. Galef, Jr., Animal Behaviour, 66, 399. Copyright 2003 by Elsevier Ltd. Adapted with permission.

es (Galef et al., 2006). It remains to be determined whether they apply to other avian species as well.

\section{References}

Amlacher, J. \& Dugatkin, L. A. (2005). Preference for older over younger models during mate choice copying in young guppies. Ethology, Ecology \& Evolution, 17, 161-169.

Bikchandani, S., Hirschleifer, D. \& Welch, J. (1992). A theory of fads, fashion, custom and cultural change as informational cascades. Journal of Political Economy, 100, 992-1026. doi:10.1086/261849

Birkhead, T. R. (1988). Behavioral aspects of sperm competition in birds. Advances in the Study of Behavior, 18, 35-72. doi:10.1016/S0065-3454(08)60309-5
Birkhead, T. R. \& Moller, A. P. (1998). Sperm Competition and Sexual Selection. London: Academic Press.

Boyd, R. \& Richerson, P. J. (1985). Culture and the Evolutionary Process. Chicago: University of Chicago Press.

Bradbury, J. W. \& Gibson, R. M. (1983). Leks and mate choice. In P. Bateson (Ed.), Mate choice, (pp. 109-140). Cambridge: Cambridge University Press.

Brooks, R. (1996). Copying and repeatability of mate choice. Behavioral Ecology \& Sociobiology, 39, 323-329. doi:10.1007/s002650050296

Brooks, R. (1998). The importance of mate copying and the cultural inheritance of mating preferences. Trends in Ecology \& Evolution, 13, 45-46. doi:10.1016/S0169-5347(97)01253-6

Crawford, L. L., Domjan, M. \& Faure, J. M. (1997). The behavior of the Japanese quail Coturnix japonica. Neuroscience and Biobehavioral Reviews, 21, 261-281. doi:10.1016/S0149-7634(96)00028-0

Dugatkin, L. A. (1992).Sexual selection and imitation: females copy the mate choices of others. American Naturalist, 139, 1384-1389. doi:10.1086/285392

Dugatkin, L. A. \& Godin, J.-G. J. (1992). Reversal of female mate choice by copying in the guppy (Poecilia reticulata). Proceedings of the Royal Society of London, B. 249, 179184. doi:10.1098/rspb.1992.0101

Galef, B. G., Jr., Watkins, S. J. \& Salehi, P. (2006). Effects of enclosure size on sexual behavior of Japanese quail (Coturnix japonica). Animal Behaviour, 120, 433-437.

Galef, B. G., Jr. \& White, D. J. (1998). Mate-choice copying in the Japanese quail, Coturnix coturnix japonica. Animal Behavior, 55, 545-552. doi:10.1006/anbe.1997.0616

Gibson, R. M., Bradbury, J. W. \& Vehrencamp, S. L. (1991). Mate choice in lekking sage grouse: the roles of vocal display, female site fidelity and copying. Behavioural Ecology, 2, 165-180. ‥ doi:10.1093/beheco/2.2.165

Gibson, R. M. \& Hoglund, J. (1992). Copying and sexual selection. Trends in Ecology \& Evolution, 7, 229-231. doi:10.1016/0169-5347(92)90050-L

Godin, J.-G. J., Herdmean, E. J. E. \& Dugatkin, L. A. (2005). Social influence on female mate choice in the guppy, Poecilia reticulata: generalized and repeatable trait copying behavior. Animal Behaviour, 69, 999-1005.

doi:10.1016/j.anbehav.2004.07.016

Hamilton, W. D. 1971. Geometry for the selfish herd. Journal of Theoretical Biology, 31, 295-311. doi:10.1016/0022-5193(71)90189-5

Hoglund, J. Alatalo, R. V., Gibson, R. M. \& Ludberg, A. (1995). Mate-choice copying in black grouse. Animal Behaviour, 49, 1627-1633. doi:10.1016/0003-3472(95)90085-3

Hoglund, J. Alatalo, R. V. \& Ludberg, A. (1992). Copying the mate choice of others? Observations on female black grouse. Behaviour, 114, 221-231. doi: $10.1163 / 156853990 \times 00130$ 
Lafleur, D. L., Lozano, G. A., Sclafani, M. (1997). Female mate-choice copyin in guppies, Poecilia reticulata: a reevaluation. Animal Behavior, 54, 579-586. doi:10.1006/anbe.1996.0452

Laland, K. N. (1994). Sexual selection with a culturally transmitted mating preference. Theoretical and Population Biology, 45, 1-15. doi:10.1006/tpbi.1994.1001

Lill, A. 1971. Sexual behavior of the lek-forming whitebearded manikin (Manacus manacus trinitatis Hartert). Zeitschrift fur Tierpsychologie, 36, 1-36.

Nordell, S. E. \& Valone, T. J. (1998). Mate choice copying as public information. Ecology Letters, 1, 74-76. doi:10.1046/j.1461-0248.1998.00025.x

Ophir, A.G. \& Galef, B.G., Jr. (2003a). Female Japanese quail affiliate with live males they have seen mate on video. Animal Behaviour, 66, 369-375. doi:10.1006/anbe.2003.2229

Ophir, A. G. \& Galef, B. G. Jr. (2003b). Female Japanese quail that 'eavesdrop' on fighting males prefer losers to winners. Animal Behaviour, 66, 399-407.

doi:10.1006/anbe.2003.2230

Ophir, A. G. \& Galef, B. G., Jr. (2004). Sexual experience can affect use of public information in mate choice. Animal Behavior, 68, 1221-1227. doi:10.1016/j.anbehav.2003.12.023

Ophir, A. G., Persaud, K. N. \& Galef, B. G., Jr. (2005). Avoidance of relatively aggressive male Japanese quail (Coturnix japonica) by sexually experienced conspecific males. Journal of Comparative Psychology, 119, 3-7. doi:10.1037/0735-7036.119.1.3

Persaud, K. N. \& Galef, B. G., Jr. (2004). Fertilized female quail avoid conspecific males: female tactics when potential benefits of new sexual encounters are reduced. Animal Behaviour, 68, 1411-1416. doi:10.1016/j.anbehav.2004.02.015

Persaud, K. N. \& Galef, B. G., Jr. (2005a). Eggs of a female quail are more likely to be fertilized by a male that she prefers. Journal of Comparative Psychology, 119, 251256. doi:10.1037/0735-7036.119.3.251

Persaud, K. N. \& Galef, B. G., Jr. (2005b). Female Japanese quail (Coturnix japonica) mate with males that harassed them are unlikely to lay fertilized eggs. Journal of Comparative Psychology, 119, 440-446. doi:10.1037/0735-7036.119.4.440

Schlinger, B. A., Palter, B. \& Callard, G. V. (1987). A method to quantify aggressiveness in Japanese quail (Coturnix c. japonica). Physiology \& Behavior, 40, 340-348. doi:10.1016/0031-9384(87)90057-6

White, D. J. \& Galef, B.G., Jr. (1999a). Affilitative preferences are stable and predict mate choices in both sexes of Japanese quail, Coturnix japonica. Animal Behaviour, 58, 865-871. doi:10.1006/anbe.1999.1210

White, D. J. \& Galef, B.G., Jr. (1999b).Mate-choice copying and conspecific cueing in Japanese quail, Coturnix coturnix japonica. Animal Behaviour, 57, 465-473. doi:10.1006/anbe.1998.1015

White, D. J. \& Galef, B.G., Jr. (1999c). Social effects on mate choices of male Japanese quail, Animal Behaviour. 57, 1005-1012. doi:10.1006/anbe.1998.1059

White, D. J. \& Galef, B.G. Jr. (2000a). 'Culture' in quail: Social influences on mate choices of female Coturnix japonica. Animal Behaviour, 59, 975-979. doi:10.1006/anbe.1999.1402

White, D. J., \& Galef, B.G., Jr. (2000b). Differences between the sexes in direction and duration of response to seeing a potential sex partner mate with another. Animal Behaviour, 59, 1235-1240. doi:10.1006/anbe.1999.1431 